\title{
A Review on the Role of Risk Management (RM) and Value Engineering (VE) Tools for Project Successful Delivery
}

\author{
Elysé Masengesho ${ }^{1}$, Ji Wei ${ }^{1}$, Nadine Umubyeyi ${ }^{2}$, Rosette Niyirora ${ }^{1}$ \\ ${ }^{1}$ School of Civil Engineering, Lanzhou Jiaotong University, Lanzhou, China \\ ${ }^{2}$ Faculty of Engineering, China University of Geosciences, Wuhan, China \\ Email: elymaombi@gmail.com, *jiwei1668@163.com
}

How to cite this paper: Masengesho, E., Wei, J., Umubyeyi, N. and Niyirora, R. (2021) A Review on the Role of Risk Management (RM) and Value Engineering (VE) Tools for Project Successful Delivery. World Journal of Engineering and Technology, 9, 109-127.

https://doi.org/10.4236/wjet.2021.91009

Received: December 15, 2020

Accepted: February 5, 2021

Published: February 8, 2021

Copyright $\odot 2021$ by author(s) and Scientific Research Publishing Inc. This work is licensed under the Creative Commons Attribution International License (CC BY 4.0).

http://creativecommons.org/licenses/by/4.0/

(c) (i) Open Access

\begin{abstract}
Both in developed and in developing countries, the construction industry is regarded as an economic investment activity without forgetting its significant relationship with national economic development due to its great contributions to the national gross domestic product (GDP) of the country. Concerning construction processes, both risk management (RM) and value engineering (VE) techniques have commonalities from the beginning up to the completion of the project due to enhancing the project value/quality, meeting the project deadline, and reducing overall project cost. VE includes resolving the uncertainty of project objectives and ensuring that the project is delivered in a value for money way. The key point of RM is to solve the uncertainty of the project itself and its results to ensure that the specifications are achieved within the prescribed time, cost, and quality constraints. This review work is comparatively and collectively focused on assessing the role of RM and VE tools for project successful delivery. It studies the points of difference and common features of the two aspects in terms of construction project delivery. So, this study concluded that in construction RM tool cannot be the chief aim of the all parties involved in the project execution because sometimes it produces itself negative results and reduces project management success. Therefore, RM needs a strong combination with VE due to the dependence of the target in identifying and assessing risks by considering the highest performance and lowest cost. The integration of RM and VE combination in a single study would avoid duplication of work and deliver better value for money thereby leading to better project outcomes.
\end{abstract}

\section{Keywords}

Managing Projects, Risk Management, Value Engineering, Proper Project 


\section{Introduction}

In both developed and developing countries, the construction industry is regarded as an economic investment activity without forgetting its significant relationship with national economic development due to its great contributions to the national gross domestic product (GDP) of the country. But even though the construction industry is more important to the country especially in development perspective, it is known that the success of the project can only be achieved when the project management is effectively delivered from the conceptual stage to the project completion stage, and the application of knowledge, skills, tools, and techniques to the project responsibilities meet the necessity of the project. It is commonly believed also that the main influence parameters of the project are time, quality, and cost while regarding the project's scope and also stakeholders' satisfaction or requirement [1]. As discovered, today's construction industry is developing day by day, but there is still some barriers or risks that make it impossible to achieve the desired goals such as poor management ability, poor technical ability and change of project objectives in which lead the project to over budget, time overrun, late completion and poor project quality. Indeed, those outcomes all depend largely on the inherent characteristics of the construction industry such as quite complex, powerful dynamics, fragile engineering environment, compact schedule, large project scale, and volume of the projects [2] [3]. According to Feng Wan [4], if those barriers or risks are not effectively prevented, they may block the smooth realization of project targets and may cause serious effects. In finding out how these serious problems can be solved, most expert persons in the construction industry believe that to complete the project delivery, the participants of the project must deal with any factors that may lead to cost overruns, project delays, poor delivery quality and high changes [5]. Therefore, the construction project management tools must be established in project management to satisfy all parties involved in the project and it should run through the whole project life cycle for increasing the effect of the opportunities and positive events while reducing the probability and effect of negative events to meet the objectives of the project. The most suitable construction project management tools are risk management and value engineering tools, because both of them are believed to be powerful project problem-solving tools; for identifying and managing risks, the risk management provides a systematic process to take actions when risks occur. It helps to determine the different project goals, improve project control, increase chances for success, improve communication between all project participants, and facilitate decision-making and priority activities [6]. On the other side, the Value Engineering tool from the beginning of the project up to the completion stage as mentioned by [7] [8] is a 
systematic method to improve the "value" of products and services by testing their functions. In other words, it is successful because it identifies chances, eliminates unnecessary costs, and ensures quality, reliability, performance, and other key factors that meet customer expectations. Thus, based on the vital role of both risk management and value engineering tools provide in construction projects process, undoubtedly, they have a huge impact on the successful delivery of the project without causing any trouble in terms of quality, reliability, safety and improving the performance of the entire life cycle of the project.

This review work is comparatively and collectively focus on assessing the role of risk management and value engineering tools for project successful delivery. It studies the points of difference and common features of the two aspects in terms of construction project delivery.

\section{Literature Syntheses}

\subsection{Definitions and Historical Backgrounds}

Both RM and VE techniques have the common targets into construction projects process from the beginning up to the completion of the project due to enhancing the project value/quality, meeting the project deadline, and reducing overall project cost. The term "risk management" is defined as an act of classifying, analyzing or accessing, and replying to unpredictable risks that exist during the implementation of a project [9]. It includes maximizing the opportunity and effect of positive events and reducing the possibility and effect of negative events to achieve project objectives [10]. Risk management involves defining the origin of uncertainty (risk identification), estimating the effects of uncertain events (risk analysis), giving reply schemes based on waited results, and finally based on actual results and emerging risk feedback, executing identification, analysis and response generation steps during the life cycle of a project to assure that project goals are met [11].

The theme of RM has existed for hundreds or even thousands of years [12]. The first appearance of RM can be traced back to the Tigris-Euphrates valley at the ending period of $3200 \mathrm{BC}$ with Asipu, who worked as a Risk Consultant [13] [14]. However, Dallas [12] said that all RM concepts began with gambling. Furthermore, archaeologists have evidence that gambling took place many years ago [13]. Besides, Hertz [15] put forward the real concept of risk analysis in his article "risk analysis in capital investment" Baker et al. [16]. However, many years ago risk management was utilized in the construction sector [17]. In the 1980s, RM emerged as an independent new field in the industry of construction [18].

On the other hand, According to W. T. Chen et al. [19], Value Engineering (VE) is defined as an organized discipline that usages a combination of common sense and technical skills to settle and remove unnecessary the whole project costs. VE has been widely used in the construction industry and has become an indispensable part of many project developments. The results of VE practices usually ameliorate the value of any project without affecting the design function 
of the project [20]. The value engineering technique began in the Second World War when General Electric Company (GEC) faced a serious problem of shortage of materials in which they were unable to meet the needs of war equipment. To defeat that critical problem, GEC had to replace scarce materials with other alternative materials that are cheaper, more beneficial, and better in performance [1].

In 1947, Lawrence D. miles was an employee Engineer at General Electric Company (GEC). He proposed many ideas and techniques to choose alternative materials to be utilized to find value in products and he developed a function-based approach that has been successfully validated. The new method was more productive so that VE was a way to produce high production and operation efficiency at the lowest production cost. In 1985, the value engineering procedure was widely recognized around the world [21].

Since its first adoption in the 1950s, Value Engineering has become a standard exercise for many government agencies and private engineering companies and contractors. It is widely used in construction projects and has become an indispensable part of developing most of the civil infrastructural projects. In the construction projects, value engineering has been implemented for half a century in aiming to provide innovative ideas and answers for improving project value [20].

In 1996, McDowell said that value engineering techniques began to be applied to all types of industries, especially in manufacturing and it was expanded to all types of economic fields including construction in which saved billions of dollars. In particular, the rapid expansion of this technique in the construction industry has become a mandatory necessity for many public projects in the United States. After entering the construction industry, to adapt to its unique characteristics the academic research and practitioners have worked together to develop some methods for the construction industry [22].

Generally, both aspects are dedicated to protecting the value while trying to reduce any related to the upcoming project. In addition to that, the conceptual phase is the most important phase of all in terms of principles application.

\subsection{The Need for RM and VE in Construction Management}

It is more important to know the scale of construction projects that RM and VE should be easily fitting because this will help the project's participants to use them in an efficient manner.

To begin with a good understanding of the project's risks and its consequences can enable project participants to take measures to reduce their negative impact [23]. Lack of effective project risk management methods will have many unpleasant impacts on the parties involved in a project because of the lack of measures to avoid the risks in the project [24]. Therefore, RM can be applied for all construction projects depending on the project size, project nature, and project complexity [25]. In small construction projects, it may only include team review and simple risk registration, while for more complex projects, a complete 
workshop and risk modeling is required [26]. Using the risk management process in different projects can greatly improve the performance of construction project management. The target of the risk management process is not totally to eliminate all project risks. The main aim is to establish an organized model that enables management to manage project risks and the most important key risk in a more effective way [27].

On the other side, the goal of the Value Engineering study is to achieve the necessary functions with the lowest project life cycle cost. This can be achieved by using new materials, innovating design, simplifying the construction process, innovating construction methods, reducing construction cost and time, improving construction quality and safety, and minimizing environmental impacts [20]. Hence, according to Khaled Ali Alabd Ahmed [22], no matter how large or small the construction project is, generally the construction sector is a significant field for VE because it is the key to the project success as well it provides the basis for improving the value of construction funds. It also focuses on value rather than cost and seeks the best balance between cost, quality, and time. Because it provides a way to integrate into the building process that no other building management structure can provide.

\subsection{The Benefits of Risk Management (RM) and Value Engineering (VE)}

As usual, the successful delivery of a project should only be achieved if all the appropriate construction management tools used in the construction industry have greater advantages to the development of the industry and are used properly throughout the contribution of each part involved in the project. Based on [28]-[34] researchers, the following are the benefits of RM in construction projects:

1) Benefits of risk identification: Risk identification helps to stay calm during times of crisis. This means that all the most likely risks to happen and the plan of prioritizing the risks must be executed without any assumptions. It helps to solve the risk and thus understand the upcoming problems.

2) Benefits of risk analysis/assessment: It bases on the identified tasks to assist the project's impact. This stage bases on the discussed ideas among the involved parties. Its biggest advantage is that it can deal with the final problem and provide more possible answers. It has a sense of all views, which becomes a sense of responsibility for every kind of social life for any project or business. Participation in such assessments will help to address the risks.

3) Risks minimization: The risks that are dealt with in a given evaluation plan are foreseeable in the construction project function. It enables the project management team to accelerate data to change contingent policies that were successfully carried out in the mapping construction project functionality. The project risk management team is responsible for minimizing implemented threats (negative effects) and maximizing opportunities (positive aspects) by identifying and managing threats at different stages of the project organization 
to improve decision making and choosing of alternatives, and provide more opportunities. By reducing potential and unexpected incidents, customers can concentrate on their energy and obtain stable income.

4) Successful project strategies: It has operational efficiency that can be achieved after the negative risks in the project are mitigated/controlled. In terms of handling measures, it has policies of the contingent for the temporary project preparation. Risk management is effective and helpful in avoiding, reducing or managing all project risks where it improves the productivity of employees in the project, and offers an important role in increasing the value of money to the project by managing the risks and uncertainties; thereby it provides the best value for the project.

5) Saving of time and cost: Risk management threatens the completed tasks in the construction project strategy. It saves the entire life cycle cost of the construction project, and prevents waste and supplement the planned progress time of the project activities. The project risk management team provides better cost and time estimates earlier than other deterministic techniques to avoid over expenditures that could invalidate the project's economic condition, and saves costs and increases project value by identifying, analyzing, assessing, and answering the risks related with options that provide better value to the project.

6) Values shareholders: The main goal of risk management is to make great efforts in managing the shareholders' ability and capacity to deal with some of the issues/risks raised in the project, and to assume the company's expanded decision-making role. In the current kind and expected regulatory recruitment of any kind of construction project, it has a precise decision-making process. From here, stakeholders into the project decide if the potential advantages associated with the work are sufficient to ensure acceptance of the relevant risks.

7) Provides guidance: It provides advanced guidance about the frameworks enabled in the experiences and assesses the risks modeled in the risk strategy. It has an advanced risk management methods that link the knowledge gained with the consequences of other risks. It improves the control level of the entire project and supports more effective problem-solving procedures on a more realistic basis.

8) Reduces effect and loss: There is a clearer procedure for risk management when a pre-planned schedule or goal is missing. It assures that the risk management team analyzes all possible outcomes independently and objective assessments as it takes on the challenge.

9) Collaborated work: Risks base on returns and even generate benefits. Risk management deals with the possibility of fulfilling responsibilities through project actions. It is recommended that project managers must focus on the risks of challenges proposals that can be defined as available. The main incentives factors may have a clear awareness and understanding of the possible risks in the project, and the workers may provide a better understanding of the potential effects of uncontrollable risks and how to prevent them. 
Speaking on the benefits for VE, in principle, improvements and preservation methods should be limited. The main reasons for the application of value engineering technique in construction projects are high cost of project implementation, the large distance between design and implementation, difficulty in project implementation, high complexity of projects, lack of basic information in construction projects, lack of connection between the design of construction projects and beneficiaries, improvement of technical progress and standards in construction projects, creativity, the change of regulations, employer's demand, environmental, social conditions, economic conditions, technical characteristics of design and use mode of resources. It is worth noting that the improvement brought by value engineering is not due to the lack of enough study or carelessness in construction technical and economic investigation but due to time interval between the design phase, implementation phase and operation phase, creativity, and cooperation of the study team. With the participation of these subjects, the value engineering technique in construction projects will help them to be greatly improved and saved [35]. Thus, Value engineering is considered a very effective approach that must be understood at all levels of project management and must be accepted every part of the world in the construction industry [36].

The following are the benefits of VE as listed by [37] in six main classes:

1) It helps in determining the best design option.

2) It helps in reducing and saving the overall project's life cycle cost.

3) To identify project problems and arise real answers solutions to them.

4) To improve the quality of the project products in the present and future.

5) To enhance reliability, availability, and client during the project starting process until the project completion.

6) It is used for saving time and resources.

\subsection{Application Methodology of RM and VE Concepts}

\section{(Risk Management)}

From a construction perspective, the risk is often seen as an event that affects the main objectives of a particular project in terms of cost, time, and quality [38]. Thus, risk must be prevented before declining the project performance throughout reducing, managing, transferring, sharing, or accepting it but cannot be overlooked [39] [40]. Risk management works throughout three main stages similar to VE as pre-workshop, workshop, and post-workshop. These stages are explained as follows:

\section{1) Pre-workshop stage}

In this pre-workshop stage, some activities must be put into consideration as very important in the project. The interview with stakeholders is made for getting all general feeling for the principal concerns of all involved parties in the project. Depending on the information quality gained during the interview session, some practitioners take it as a crucial part of the process and others take it 
as the chance for an honest exchange [25] [41]. Moreover, this tool allows stakeholders to talk about risks that they can see and gives them a feeling of involvement in the process and ownership of the identified risk, and this might lead to more acceptances of any measures executed to decrease risk [29].

\section{2) Workshop stage}

The main phases under the workshop stage are more explained below.

Risk management plan: Within this phase, the project targets must be clear and understandable to all parties involved, and focusing on the risk procedure around the particular necessities of the specific project, recording the results in the plan of risk management and showing how the risk management will be executed for any particular project [42]. The aims of risk management should be accorded before entering on risk identification.

Risk identification: Risk identification is the procedure of discovering and assessing the vital role of the risks associated with construction projects [43]. The main idea behind risk identification seems to be very famous and practiced and of course, it could have a great impact or consequences on project growth and its success [44] [45]. Risk identification however in construction projects is based on a) identifying the better essential input data b) having a most and best skills of the relevance of the procedure $c$ ) identifying risks with their potential impacts to the construction project $\mathrm{d}$ ) providing data for those who are in charge of decisions making, e) finding the all-risk causes, f) identifying entities impacted by crucial risks [46] [47]. Various techniques are used to identify risks on construction projects including Brainstorming, Delphi method, interview with expert persons, past experience, and checklist as shown in Table 1 below [10] [48] [49] [50].

On any construction project, there are two kinds of project risk: known risk which is assessed throughout the five stages of the project, and unknown risk. Known risks should be handled with human being capability through risks identifying, risks analyzing for planning the response to them while unknown risks human being cannot [45].

Risk analysis: Risk analysis is a process of vital evaluation of prospective risks, ordering them according to importance, and permitting the project management team to choose the best significant ones [23]. In risk analysis, two main methods are developed as a quantitative method and qualitative method [49] [51]. The choice of better method depends on the following reasons: project type and scope of the project, available data, financial significance and time availability, the skills and experience of the analysts, the scale of the invention and the quality objectives of the results [52]. According to the severity of the risk, the risk is ranked to provide the basis for the priority of risk management. This means that during the risk workshop, each identified risk should be classified as having a high, medium, or low effect and recorded in the risk register. The first attempt at rapid classification should be based on the cost and probability of occurrence. This refers to Table 2 below of Risk ranking matrix. 
Table 1. Main techniques used to identify risks in construction projects.

\begin{tabular}{|c|c|}
\hline Tech & ions \\
\hline Brainstorming & $\begin{array}{l}\text { This technique is the most popular and useful techniques for risk identification in } \\
\text { a risk management workshop. Under this technique, every part involved in the } \\
\text { project knows each other and works together to find out the risk factors that } \\
\text { affect the whole project, the new risks, and the new management systems. }\end{array}$ \\
\hline Delpl & $\begin{array}{l}\text { This method is like brainstorming technique but all involved parties do not know } \\
\text { each other and they do not work together and during identifying the risk factors } \\
\text { process there is no consulting each other participants. }\end{array}$ \\
\hline $\begin{array}{l}\text { Interview with } \\
\text { expert persons }\end{array}$ & $\begin{array}{l}\text { The persons who have enough experience in a project play a vital impact by } \\
\text { solving small and big problems that exist in the project. Thus, all participants in } \\
\text { the construction project must be interviewed in the process of finding the } \\
\text { identification of the factors that affect risk. In general under this technique, for } \\
\text { getting feedback to risks appeared in project the project risk management } \\
\text { leadership must establish the method of historical data analysis of past or present } \\
\text { project, risk analysis and lessons learned }\end{array}$ \\
\hline Past $e$ & $\begin{array}{l}\text { Past experience of historical data from past projects that are similar to the present } \\
\text { project can only be useful in a determined number of considerations for } \\
\text { identification of the risk factors. In making comparison both characteristics of } \\
\text { projects will provide a clear understanding of the common risk factors. }\end{array}$ \\
\hline Checklists & $\begin{array}{l}\text { First of all, it is necessary to know the essentials items that cab fail in previous } \\
\text { projects because it is very useful and helpful in risk identification. This will help a } \\
\text { team of project managers to be aware of the risks present and allow them to be } \\
\text { involved in the risk identification process for looking implementation of some } \\
\text { measures to reduce the risks and its effects on the project. Generally, the checklist } \\
\text { of the risks found in the past projects and undertaken measures to deal with these } \\
\text { risks provides a starting point of the process of risk identification. }\end{array}$ \\
\hline
\end{tabular}

Table 2. Risk ranking matrix.

\begin{tabular}{ccccc}
\hline & & \multicolumn{3}{c}{ Ranking } \\
\hline \multirow{3}{*}{ Cost } & High & Medium & High & High \\
& Medium & Low & Medium & High \\
& Low & Low & Low & Medium \\
& & Low & Medium & High \\
& & Occurrence Probability & \\
\hline
\end{tabular}

The qualitative methods are most relevant in case risks can be located anywhere on a descriptive scale from low point to high point [53]. This method is primarily focused on the right risk's probability estimation and scale of accompanied more consequences, participants experience, instinct, and judgment decision [54] [55]. First of all, it helps to discover possible hazards, analyze and determine them, and eliminate certain hazards in time because the project risk probability is small.

On the other hand, the quantitative methods are used to find the spreading of probability and effects of the risks identified and they are based on statistics, estimations of arithmetic [53]. Nevertheless, if enough data are affordable at the maximum level it can provide target outcomes. Hence, the results can impor- 
tantly vary from each and one analyst to another. Accordingly, the quantitative method stays the favored choice by almost practitioners [55].

The following Table 3 showing the summary of several techniques to be used in the construction industry for risk analysis.

Risk response: According to [58] [59], Risk response is the designed documents process for Risk management that is employed to deal with the identified and analyzed risks by enhancing chances and decreasing any menaces to projects aims. The main objective of the risk response process is to enhance the level of risk control, cut down the negative effect of the risk, and remove as a lot as possible the potential effect [60]. The main important techniques to confront the risks in a construction project are risk avoidance, reduction, transfer, and risk retention as it is described below [38] [52] [61]-[67].

Risk avoidance technique: This technique based on protecting the whole project objectives risks with their effects by ensuring the project that from now the risk is not going to continue. Naturally, not all risks can be avoided or eliminated, but some risks have demonstrated experience in many different projects that could be avoided and removed.

Risk reduction technique: The target of this technique is to mitigate or reduce and overcome probability or consequences of a special risk to any satisfactory level, for taking some procedures that help in reducing the potential for risk more beneficial than to look the measures that should be taken to deal with the negative impact of that risk. The explanation of risk reduction may be applied at each phase of the project, from the designing period up to the completion period.

Risk transference technique: Risk transference intends to shift all negative effects of risk from one party to another party called the third party without removing or changing anything about how much amount of risk and how essential the risk origins are. It means that the duty of project risk management must be shifted to another party without avoiding the hazard and its consequences.

Risk-retention technique: This technique means there is no need to deal or control the risk with its consequences due to the risk management team is unable to take any other technique and sometimes due to the issue of a short time as well as financial means. The only thing the risk management can do is to accept it without changing the project design to handle the project's risk.

Table 3. Several risk analysis techniques [38] [56] [57].

\begin{tabular}{ccc}
\hline No & Qualitative Methods & Quantitative Methods \\
\hline 1 & Brainstorming & Decision tree analysis \\
2 & Straight judgment & Expected monetary value \\
3 & Cause and effect diagram & Fault Tree Analysis (FTA) \\
4 & Checklists & Fuzzy logic assessment \\
5 & Delphi & Probability analysis \\
6 & Event Tree Analysis (ETA) & Sensitivity analysis \\
7 & Risk information quality assessment & Simulation analysis \\
\hline
\end{tabular}




\section{3) Post-workshop stage}

Under this stage, the Majority assessment and analysis are conducted after the activities in the workshop stage and draft report must be released. In addition, some participants held an audit meeting with crucial key stakeholders to resolve the matters. Typically, the project's risk managers are in charge of supervising and controlling the implementation of reply plans during on risks ongoing participation [41].

\section{(Value Engineering)}

In the construction industry, the application of VE in the project uses a multidisciplinary team for ameliorating the value of it. As shown in Figure 1 below VE technique works throughout three main stages: pre-workshop stage, workshop stage, and post-workshop stage and seven phases.

Referring to Major, E. [69], at the early stage of a project, value opportunities are often strategic; with the development of the project, these opportunities begin to recede and the engineering opportunities become more frequent or dominant. Due to the changes in the nature of the project environment, formal value management studies are carried out at a very significant stage of the project, related to and the cost estimates updates, as summarized below.

Feasibility, Concept and Preliminary Design

Value engineering is a structured approach to define the meaning of value in the process of accomplishing specific project requirements. This is attempted by approving a common understanding of the project objectives and how the project team will achieve them. The procedure is strategic, includes challenging the necessities and approving the project objectives.

Detailed Design, Procurement, and Delivery

However, value engineering is a systematic approach that delivers the required functions at the lowest cost without compromising quality, performance, and reliability. This process is focused on project details and delivery procedures to

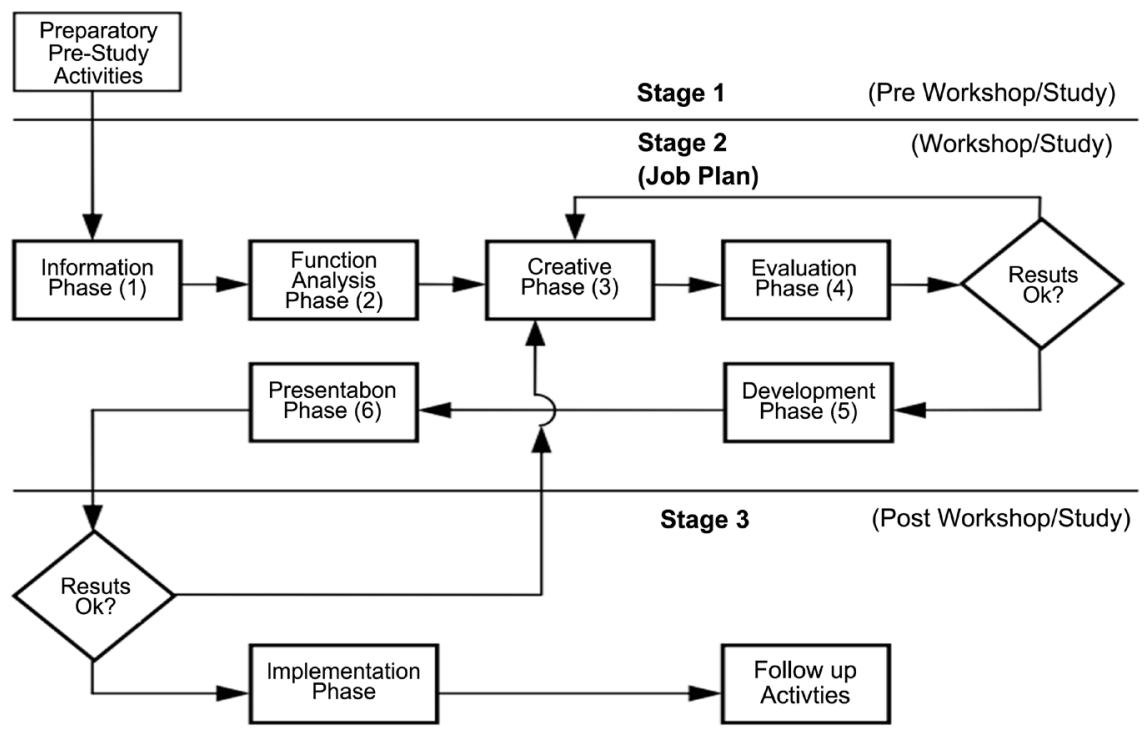

Figure 1. Adapted from SAVE international [68]. 
ensure the improved efficiencies, eliminate over design, and hence to maximize value.

Each value engineering study can be divided into the following distinct phases [22] [35] [37] [70] [71] [72].

\section{Information and Function Analysis phases:}

The information phase process allows all participants to better understand the value engineering workshop process and project nature. Finally, it determines the scope of the problem to be solved, improve objectives and evaluation elements; data collection and analysis; and build cohesion among project management team members. While the function analysis phase to all participants is to understand well the project through the project perspective function and determine the areas that are most productive to the study. This is a fundamental activity that distinguishes value engineering compare to other problem-solving methods. At this phase, the team members must orient their thinking in terms of project functions and the overall costs associated with each function. The main activities to be performed under these phases are summarized in Table 4 below.

\section{Creativity and Evaluation phases:}

The creative phase presents ideas for all potential ways to fulfill the needed functions selected for further study within the project. Through several recognized techniques used by the value engineering team), a large number of ideas can be received to produce many optimal solutions that can be used to solve problems. While Under the evaluation phase all generated ideas about saving time and money, investment cost, and practical to the project implementation during the creative phase must be evaluated to bring out the answers. It means that all the alternatives must be ranked and critically assessed by the VE team to identify the best opportunities for project value improvement. The main activities to be performed under these phases are summarized in Table 5 below.

\section{Development and Presentation phases:}

The development phase determines the best alternatives for improving value to the decision-maker. In this phase, detailed technical analyses are made for the remaining alternatives. It means that during this phase the VE team has to be more familiar with the accurate method to be used and study its impact over the overall project cost and construction period. While the purpose of the presentation phase is to obtain a commitment to follow a course of action and initiate an alternative. The value engineering team selects the best alternatives and presents them to the clients and project stakeholders after the workshop. This presentation allows the management or decision-makers to select compatible decisions with the achievement of the project objectives. The main activities to be performed under these phases are summarized in Table 6 below.

\section{Implementation and Follow up phases:}

The purpose of the implementation phase is to obtain final approval of the proposal and to ensure the applicability of the confirmed value alternatives and actualizing and confirming the planned advantages of a value study. While the 
purpose of the follow-up phase is to tracking activities of implementing value study results and improve value methodology for future studies in similar construction projects. The main activities to be performed under these phases are summarized in Table 7 below.

Table 4. The VE activities under information and function analysis phases.

\begin{tabular}{lll}
\hline No & \multicolumn{1}{c}{ Information } & \multicolumn{1}{c}{ Function Analysis } \\
\hline 1 & $\begin{array}{l}\text { Project Team presents the original design } \\
\text { concepts }\end{array}$ & $\begin{array}{l}\text { Find out the project functions, availabilities } \\
\text { of resources and arranging them }\end{array}$ \\
2 & Identify program issues and constraints & $\begin{array}{l}\text { Discover greater possible system and } \\
\text { component problems to be discussed }\end{array}$ \\
3 & Confirm the most current project concept & Select functions to focus the creativity phase \\
4 & Visit site or facility & $\begin{array}{l}\text { Find out the best chances for performance } \\
\text { improvement }\end{array}$ \\
& $\begin{array}{l}\text { Approving the project targets, plans, and } \\
\text { budgets }\end{array}$ & $\begin{array}{l}\text { Provide the cost estimation of performing } \\
\text { each function }\end{array}$ \\
\hline
\end{tabular}

Table 5. The VE activities under creativity and evaluation phases.

\begin{tabular}{|c|c|c|}
\hline No & Creativity & Evaluation \\
\hline 1 & Creative warm-up exercises & $\begin{array}{l}\text { Discussing how ideas impact project performance } \\
\text { by taking out low-potential ideas and choosing the } \\
\text { best ones }\end{array}$ \\
\hline 2 & $\begin{array}{l}\text { Establishing basic principles to protect the } \\
\text { creative environment under development }\end{array}$ & $\begin{array}{l}\text { Ranking the all determined opportunities based } \\
\text { on their appropriateness }\end{array}$ \\
\hline 3 & $\begin{array}{l}\text { Generating alternative ideas that can } \\
\text { improve project value }\end{array}$ & $\begin{array}{l}\text { List the advantages and disadvantages of each idea } \\
\text { and establish evaluation criteria }\end{array}$ \\
\hline
\end{tabular}

Table 6. The VE activities under development and presentation phases.

\begin{tabular}{|c|c|c|}
\hline No & Development & Presentation \\
\hline 1 & $\begin{array}{l}\text { Preparing and conducting a life cycle cost } \\
\text { analysis and alternative design }\end{array}$ & $\begin{array}{l}\text { Exchange information with the project } \\
\text { team about the workshop objectives and } \\
\text { scope }\end{array}$ \\
\hline 2 & $\begin{array}{l}\text { Determine the most beneficial alternatives to be } \\
\text { developed into proposals so that owner and other } \\
\text { project stakeholders understand the intent of } \\
\text { proposal and benefits to the project }\end{array}$ & $\begin{array}{l}\text { Identify the team members and recognize } \\
\text { their contributions in demonstrating the } \\
\text { validity of the data sources and supporting } \\
\text { documentation }\end{array}$ \\
\hline 3 & $\begin{array}{l}\text { Develop implementation of action plans includes } \\
\text { a project description, sketches, basic design } \\
\text { concepts, technical information and cost } \\
\text { summaries }\end{array}$ & $\begin{array}{l}\text { Present the costs and benefits, advantages } \\
\text { and disadvantages, and impact of each } \\
\text { alternative according to the stated action } \\
\text { plan and implementation schedule }\end{array}$ \\
\hline
\end{tabular}

Table 7. The VE activities under implementation and follow up phases.

\begin{tabular}{lll}
\hline No & \multicolumn{1}{c}{ Implementation } & Follow up \\
\hline 1 & $\begin{array}{l}\text { Prepare a written report of the study results, Obtain copies of all completed implementation } \\
\text { lessons learned through implementation }\end{array}$ & actions \\
\hline
\end{tabular}




\section{Continued}

Monitor progress and enhance the probability of approval

Obtaining implementation warranty fo construction projects

Identifying where chances were lacked

4 Obtaining implementation warranty for construction projects

Holding a meeting with the subject of

5 implementation to determine each value alternatives formation

Determining a time interval to investigate and implement each of value alternatives

and Pursuing value achievements resulted from the implemented alternatives

Considering how the experiences have

7 developed new capabilities in creating and managing an executable design
Compare actual results with original expectations including the study results, previously learned lessons or other recorded cases in construction project implementation

Submit cost savings or other benefit reports to management

Conduct a lessons-learned analysis of the study to identify problems encountered and recommend corrective action for the next study

Specifying innovation barriers and finding their causes

Initiate recommendations for potential future VE studies on ideas evolving from the study just completed

Returning to value study and thinking about the way of developing experience with new capabilities in construction projects

\section{Conclusion}

In construction project management, value engineering and risk management have commonalities from the beginning up to the completion of the project due to enhancing the project value/quality, meeting the project deadline, and reducing overall project cost. They both evaluate the uncertainty associated with projects and could, therefore, be considered as a joint technique, it is like two faces of the same coin. While VE is committed to solving uncertainties in project objectives and ensuring that the project is delivered in a value for money manner, RM is committed to solving the uncertainties in the project itself and its results to ensure that the specifications are accomplished within the prescribed time, cost and quality constraints. By combining RM and VE in the key stages of the construction project, project participants can achieve project goals at the lowest cost, reduce unnecessary workload, and allow the project team to focus on finding the right direction of the project to improve project delivery efficiency and risk reduction rather than dividing the team into two or more opposing sides. Therefore, the integration of RM and VE combination in a single study would avoid duplication of work and deliver better value for money thereby leading to better project outcomes.

\section{Conflicts of Interest}

The authors declare no conflicts of interest regarding the publication of this paper.

\section{References}

[1] Garomsa, T., De Castro Agon, E. and Assefa, S. (2019) Concept of Value Engineer- 
ing and Current Project Management Practice in Ethiopian Building Construction Projects. American Journal of Civil Engineering, 7, 1-8. https://doi.org/10.11648/j.ajce.20190701.11

[2] Rostami, A. and Oduoza, C.F. (2017) Key Risks in Construction Projects in Italy: Contractors' Perspective. Engineering, Construction and Architectural Management, 24, 451-462. https://doi.org/10.1108/ECAM-09-2015-0142

[3] Choe, S. and Leite, F. (2017) Assessing Safety Risk among Different Construction Trades: Quantitative Approach. Journal of Construction Engineering and Management, 143, Article ID: 04016133. https://doi.org/10.1061/(ASCE)CO.1943-7862.0001237

[4] Wang, F. (2013) The High-Speed Railway Construction Project Quality Risk Management Theory and Practice. Railway Engineering Construction Management of Exploration and Practice. Tsinghua University Press, Beijing.

[5] Constant, M., Theoneste, B. and Marie, J.K. (2018) The Role of Effective Collaboration for Successful Delivery of Construction Projects. Proceedings of the Fourth Australasia and South-East Asia Structural Engineering and Construction Conference, Brisbane, 3-5 December 2018, CON-17-1-CON-17-6.

[6] Marcelino-Sádaba, S., Pérez-Ezcurdia, A., Echeverría Lazcano, A.M. and Villanueva, P. (2014) Project Risk Management Methodology for Small Firms. International Journal of Project Management, 32, 327-340. https://doi.org/10.1016/j.ijproman.2013.05.009

[7] Babu, S., Rajenthirakumar, D, Gomathinayagam, A. and Nivas Krishnan, K. (2016) Cost Reduction of Arm Cross Bar of Wheel Loader through Value Engineering. International Journal of Engineering Research, 5, 299-302.

[8] Leu, J.-D. and Lee, L.J.-H. (2016) Enterprise Resource Planning (ERP) Implementation Using the Value Engineering Methodology and Six Sigma Tools. Enterprise Information Systems, 11, 1243-1261. https://doi.org/10.1080/17517575.2016.1215537

[9] Kang, L.S., Kim, S.-K., Moon, H.S. and Kim, H.S. (2013) Development of a 4D Object-Based System for Visualizing the Risk Information of Construction Projects. Automation in Construction, 31, 186-203. https://doi.org/10.1016/j.autcon.2012.11.038

[10] Tipili, L.G. and Ibrahim, Y. (2015) Identification and Assessment of Key Risk Factors Affecting Public Construction Projects in Nigeria: Stakeholders' Perspectives The Nigerian Institute of Quantity Surveyors 2nd Research Conference, Akure, 1-3 September 2015, 707-721.

[11] Irlayici Cakmak, P. and Tezel, E. (2019) A Guide for Risk Management in Construction Projects: Present Knowledge and Future Directions. Risk Management in Construction Projects. IntechOpen, London. https://doi.org/10.5772/intechopen.84361

[12] Dallas, M.F. (2006) Value \& Risk Management: A Guide to Best Practice. Blackwell Publishing Ltd., Oxford. https://doi.org/10.1002/9780470759448

[13] Covello, V.T. and Mumpower, J. (1985) Risk Analysis and Risk Management: An Historical Perspective. Risk Analysis, 5, 103-120. https://doi.org/10.1111/j.1539-6924.1985.tb00159.x

[14] Grier, B. (1981) The Early History of the Theory and Management of Risk. Judgement and Decision Making Group Meeting, Philadelphia, 1-13.

[15] Hertz, D.B. (1964) Risk Analysis in Capital Investment. Harvard Business Review, 42, 95-106. 
[16] Baker, S., Ponniah, D. and Smith, S. (1999a) Survey of Risk Management in Major U.K. Companies. Journal of Professional Issues in Engineering Education and Practice, 125, 94-102. https://doi.org/10.1061/(ASCE)1052-3928(1999)125:3(94)

[17] Weatherhead, M., Owen, K. and Hall, C. (2005) Integrating Value and Risk in Construction. Construction Industry Research and Information Association, London.

[18] Thevendran, V. and Mawdesley, M.J. (2004) Perception of Human Risk Factors in Construction Projects: An Exploratory Study. International Journal of Project Management, 22, 131-137. https://doi.org/10.1016/S0263-7863(03)00063-2

[19] Chen, W.T., Chang, P.Y. and Huang, Y.H. (2010) Assessing the Overall Performance of Value Engineering Workshops for Construction Projects. International Journal of Project Management, 28, 514-527.

https://doi.org/10.1016/j.ijproman.2009.08.005

[20] Zhang, X., Mao, X. and Abou Rizk, S.M. (2009) Developing a Knowledge Management System for Improved Value Engineering Practices in the Construction Industry. Automation in Construction, 18, Article ID: 777789. https://doi.org/10.1016/j.autcon.2009.03.004

[21] Swetha, S., Smruthi, N.R. and Aleem, M. (2016) Application of Value Engineering in Building Construction. International Journal of Advance Research in Science and Engineering, 5, 253-267.

[22] Ahmed, K.A.A. (2016) Concept of Value Engineering in Construction Industry. International Journal of Science and Research, 5, 1-7.

[23] El-Sayegh, S.M, and Mansour, M.H. (2015) Risk Assessment and Allocation in Highway Construction Projects in the UAE. Journal of Management in Engineering, 31, Article ID: 04015004. https://doi.org/10.1061/(ASCE)ME.1943-5479.0000365

[24] Serpella, A.F., Ferrada, X., Howard, R. and Rubio, L. (2014) Risk Management in Construction Projects: A Knowledge-Based Approach. Procedia-Social and Behavioral Sciences, 119, 653-662. https://doi.org/10.1016/j.sbspro.2014.03.073

[25] Wood, G.D. and Ellis, R.C.T. (2003) Risk Management Practices of Leading UK Cost Consultants. Engineering, Construction and Architectural Management, 10, 254-262. https://doi.org/10.1108/09699980310489960

[26] Mlybari, E.A. (2011) Managing Value, Requirements and Risk in the Appraisal Stage of UK Construction Projects. Ph.D. Thesis, University of Leeds, Leeds. http://etheses.whiterose.ac.uk/id/eprint/2403

[27] Bahamid, R.A. and Doh, S.I. (2017) A Review of Risk Management Process in Construction Projects of Developing Countries. IOP Conference Series. Materials Science and Engineering, 271, Article ID: 012042. https://doi.org/10.1088/1757-899X/271/1/012042

[28] Reddy, C. (2016) What Is Risk Management: Advantages and Disadvantages? https://content.wisestep.com/advantage-disadvantage-risk-management/

[29] Smith, N.J., Merna, T. and Jobbling P. (2006) Managing Risk in Construction Projects. 2nd Edition, Blackwell Publishing, Oxford.

[30] Smith, N. (2003) Basic Theory of Risk Management. In: Smith, N., Ed., Appraisal, Risk and Uncertainty. Thomas Telford Publishing, London, 40-48.

[31] Holt, R. (2004) Risk Management: The Talking Cure. Organization, 11, 251-270. https://doi.org/10.1177/1350508404041615

[32] Othman, A.A.E. (2005) Value and Risk Management Protocol for Dynamic Brief Development in Construction. Emirates Journal for Engineering Research, 10, 23-36. 
[33] Thomas, P. (2009) Strategic Management. Course at Chalmers University of Technology, Gothenburg.

[34] Cooper, D., Grey, S., Raymond, G. and Walker, P. (2005) Project Risk Management Guidelines: Managing Risk in Large Projects and Complex Procurements. John Wiley \& Sons, Ltd., Chichester. https://www.wiley.com/en-us

[35] Rad, K.M. and Aminoroaya, Y.O. (2016) The Methodology of Using Value Engineering in Construction Projects Management. Civil Engineering Journal, 2, 262-269. https://doi.org/10.28991/cej-030986

[36] Gowrisankar, N.T.V., Tom, N. and Gowrisankar, V. (2015) Value Engineering In Residential House Construction. International Journal of Civil Engineering and Technology, 6, 46-52.

[37] Itsekor, B.-E.M. (2018) Value Engineering as a Tool for Sustainable Development in the Construction Industry in Nigeria. 4th Research Conference of the Nigerian Institute of Quantity Surveyor, Owerri Imo State, 1-17.

[38] Project Management Institute (2013) A Guide to The Project Management Body of Knowledge (PMBOK Guide). Project Management Institute, Newtown Square.

[39] Mason, J. (2016) Construction Law: From Beginner to Practitioner. Routledge, London. https://doi.org/10.4324/9781315678634

[40] Tembo Silungwe, C.K. and Khatleli, N. (2018) An Analysis of the Allocation of Pertinent Risks in the Zambian Building Sector Using Pareto Analysis. International Journal of Construction Management, 20, 321-334. https://doi.org/10.1080/15623599.2018.1484853

[41] Wood, G. and Ellis, R. (2003) Existing Risk Management Approaches in Civil Engineering. In: Smith, N., Ed., Appraisal, Risk and Uncertainty, Thomas Telford Publishing, London, 22-33.

[42] Hillson, D. (2002) Extending the Risk Process to Manage Opportunities. International Journal of Project Management, 20, 235-240. https://doi.org/10.1016/S0263-7863(01)00074-6

[43] Al-Bahar, J.F. and Crandall, K.C. (1990) Systematic Risk Management Approach for Construction Projects. Journal of Construction Engineering and Management, 116, 533-546. https://doi.org/10.1061/(ASCE)0733-9364(1990)116:3(533)

[44] Hassanein, A.A. and Afify, H.M. (2007) A Risk Identification Procedure for Construction Contracts-A Case Study of Power Station Projects in Egypt. Civil Engineering and Environmental Systems, 24, 3-14. https://doi.org/10.1080/10286600600910104

[45] Crnković, D. and Vukomanović, M. (2016) Comparison of Trends in Risk Management Theory and Practices within the Construction Industry. e-GFOS, No. 13, 1-11. https://doi.org/10.13167/2016.13.1

[46] Rostami, A. (2016) Tools and Techniques in Risk Identification: A Research within SMEs in the UK Construction Industry. Universal Journal of Management, 4, 203-210. https://doi.org/10.13189/ujm.2016.040406

[47] Szymański, P. (2017) Risk Management in Construction Projects. Procedia Engineering, 208, 174-182. https://doi.org/10.1016/j.proeng.2017.11.036

[48] El-Sayegh, S.M. (2014) Project Risk Management Practices in the UAE Construction Industry. International Journal of Project Organisation and Management, 6, 121-137. https://doi.org/10.1504/IJPOM.2014.059748

[49] Choudhry, R.M. and Iqbal, K. (2012) Identification of Risk Management System in Construction Industry in Pakistan. Journal of Management in Engineering, 29, 
42-49. https://doi.org/10.1061/(ASCE)ME.1943-5479.0000122

[50] Landage, A.B. (2016) Risk Management in Construction Industry. International Journal of Engineering Research, 5, 153-155.

[51] Tchankova, L. (2002) Risk Identification: Basic Stage in Risk Management. Environmental Management and Health, 13, 290-297. http://www.towersperrin.com https://doi.org/10.1108/09566160210431088

[52] Goh, C.S. and Abdul-Rahman, H. (2013) The Identification and Management of Major Risks in the Malaysian Construction Industry. Journal of Construction in Developing Countries, 18, 19-32.

[53] El-Dash, K. (2008) Construction Risk Management Application and Education selected. Proceeding from the 12 th International Congress on Project Engineering, Saragossa, July 2008, 390-403.

[54] Połoński, M. and Pruszyński, K. (2006) Risk Issues in the Design of Construction Works (part 1). Main Board of the Polish Association of Construction Engineers and Technicians Construction Review, 77, 46-49.

[55] Jarkas, A.M. and Haupt, T.C. (2015) Major Construction Risk Factors Considered by General Contractors in Qatar. Journal of Engineering, Design and Technology, 13, 165-194. https://doi.org/10.1108/JEDT-03-2014-0012

[56] Chapman, C. and Ward, S. (1997) Project Risk Management: Processes, Techniques and Insights. John Wiley \& Sons Ltd., Chichester.

[57] Del Cano, A. and de la Cruz, M.P. (2002) Integrated Methodology for Project Risk Management. Journal of Construction Engineering and Management, 128, 473-485. https://doi.org/10.1061/(ASCE)0733-9364(2002)128:6(473)

[58] Wang, M. and Chou, H. (2003) Risk Allocation and Risk Handling of Highway Projects in Taiwan. Journal of Management in Engineering, 19, 60-68. https://doi.org/10.1061/(ASCE)0742-597X(2003)19:2(60)

[59] Project Management Institute (2008) A Guide to the Project Management Body of Knowledge. Project Management Institute, Newtown Square.

[60] Wang, S.Q., Dulaimi, M.F. and Aguria, M.Y. (2004) Risk Management Framework for Construction Projects in Developing Countries. Construction Management and Economics, 22, 237-252. https://doi.org/10.1080/0144619032000124689

[61] Kapliński, O. (2012) Comments on Own Research: Flashback. Archives of the Institute of Civil Engineering, 13, 171-185.

[62] Joana, P., Tereso, A., Fernandes, G. and Almeida, R. (2014) Project Risk Management Methodology: A Case Study of an Electric Energy Organization. Procedia Technology, 16, 1096-1105. https://doi.org/10.1016/j.protcy.2014.10.124

[63] Dada, J.O. (2010) Strategies for Militating Risk in Construction Projects. Proceedings of the 40 th Annual General Meeting/Conference of the Nigerian Institute of Building, Asaba, 7-11 July 2010, 28-35.

[64] Smith, N.J., Merna, T. and Jobling, P. (2009) Managing Risk: In Construction Projects. John Wiley \& Sons, Oxford.

[65] Keller, S.A. (2006) Information Technology Project Management: A Concise Study. Prentice-Hall, New Delhi.

[66] Max, W.R. (2004) Project Risk Management: The Project Management Handbook. Project Management Institute, Newtown Square.

[67] Van Well Stan, D., Lindenaar, F., Van Kinderen, S. and Van Den Bunt, B.P. (2004) Project Risk Management. Kogan Page Limited, New Delhi.

[68] SAVE International (2007) Value Standard and Body of Knowledge. SAVE Interna- 
tional, Mount Royal. www.value-eng.org

[69] Major, E. (2003) Heads or Tails. Paper Presented at PMI ${ }^{\oplus}$ Global Congress 2003EMEA, Project Management Institute, Newtown Square.

[70] Jaapar, A., Maznan, N.A. and Zawawi, M. (2012) Implementation of Value Management in Public Projects. Procedia-Social and Behavioral Sciences, 68, 77-86. https://doi.org/10.1016/j.sbspro.2012.12.208

[71] Rachwan, R., Abotaleb, I. and Elgazouli, M. (2016) The Influence of Value Engineering and Sustainability Considerations on the Project Value. Procedia Environmental Sciences, 34, 431-438. https://doi.org/10.1016/j.proenv.2016.04.038

[72] Chavan, A.J (2013) Value Engineering in Construction Industry. International Journal of Application or Innovation in Engineering \& Management, 2, 18-26. 